\title{
Entre el sueño y la muerte: las tradiciones meditativas y Vapor de Max
}

\author{
JOSEP OLIVER
}

Josep Oliver (1979) es licenciado en Filología Hispánica y actualmente termina un Máster en Lengua y Literatura Modernas. Es divulgador de cómic en diversos medios, entre ellos el periódico Ultima Hora. Trabaja como profesor de Lengua y Literatura en Secundaria. También es el cocreador y guionista del cómic El joven Lovecraft.

El Camino claro parece oscuro. El camino progresivo parece regresivo. La virtud establecida parece harapienta. La gran Forma carece de forma. El Tao está oculto y no tiene nombre, pero solo él sabe cómo ayudar y completar.

Lao Tse, Tao Te King (XLI)

Quien desee ver cómo es en verdad su mente, debe liberarse de todos los pensamientos; entonces la verá como un vacío o el color del cielo.

San Nilo asceta, Filocalia

Quiero dedicar este artículo a la memoria de mi maestro el Dr. Luis Fernández Ripoll de la UIB, que sigue guiándome a través de los libros que me legó. 


\section{Introducción}

Cuando empecé a darle vueltas a este artículo, tras haber leído con fervor la obra Vapor de Max, me propuse un acercamiento desde la lectura del Tao Te King de Lao Tse, otra obra que durante los últimos diez años he releído también ávidamente. El libro del Tao Te King, obra de Lao Tse, es una de las obras referenciales del pensamiento oriental. Con más de 2.000 años, consta de 81 apartados compuestos por breves máximas. Se trata de un libro que, aún no siendo una obra religiosa, con sus reflexiones, a veces bajo la apariencia de la contradicción, dejan al lector al borde del abismo del conocimiento. Es por eso que es un libro inspirador a la hora de iniciarse en la experiencia meditativa. La palabra tao puede traducirse literalmente por "el camino", "la vía", o también por "el método" o "la doctrina", aunque no tiene un significado unívoco. Depende del contexto y puede usarse como término filosófico, cosmológico, religioso o moral. Por eso mismo resulta difícil hablar de él de una forma general, ya que si algo caracteriza el Tao precisamente es que es indefinible: "Del Tao se puede hablar, pero no del Tao eterno. Pueden nombrarse los nombres, pero no el Nombre eterno." (Tao, I).

Pero a medida que iba bosquejando lo que podía ser "Una lectura taoísta de Vapor", me di cuenta de que el texto aceptaba también una correlación más amplia. Quien esté familiarizado con el concepto de meditación verá en lo que le acontece al protagonista, Nicodemo, un reflejo del proceso de ascenso y depuración espiritual que el seguidor de cualquier senda mística experimenta. Por eso, decidí cambiar sensiblemente el enfoque del artículo para abrirlo a una lectura más amplia, en la que señalar cómo Max ejemplifica en Nicodemo ese proceso de experiencia trascendental que es común a la cábala judía, el hesicasmo cristiano, el sufismo, el zen o el yoga kundalini, por citar algunas sendas de meditación.

Todas estas escuelas meditativas, aunque con nombres y orígenes diferentes, tienen un mismo propósito: vaciar la conciencia del ser individual para llegar a un

CuCo, Cuadernos de cómic número 1. Septiembre de 2013

CuCoEnsayo 
estado superior de unión con lo eterno, superando las barreras de la carne, los afectos y el pensamiento. Vapor, de Max, habla sobre una búsqueda metafísica. Nos presenta al protagonista, Nicodemo (en adelante Nick), que se encuentra en el desierto intentando hallar la iluminación, como algunos de los santos (San Teódulo de Edesa, San Simón Estilita o San Abba Doroteo), ${ }^{1}$ porque este paraje favorece la introspección. El Tao afirma: “¿Cómo puedo conocer el mundo? Por lo que se halla en mi interior” (Tao, LIV). ${ }^{2}$ El nombre de Nicodemo, además, tiene una resonancia bíblica: remite al personaje que en el Nuevo Testamento habla en defensa de Jesús ante el tribunal. Se trata de un fariseo y quizá miembro del Sanedrín, ${ }^{3}$ que como sabio judío que reconoce la divinidad de Jesús representa un importante apoyo para el cristianismo. El Nicodemo bíblico se acerca a la figura de Jesús intrigado por sus milagros y sostiene con él una conversación sobre el renacer del espíritu. Este último dato conecta de alguna forma con el Nick de Vapor, que busca también con afán la verdad que lo libere.

Desde la primera página, se establece un diálogo entre Nick y Moisés. Moisés (o Mosh, como quiere que le llamen), con su característica estilización pop, transfiguración de Mickey Mouse y el gato Félix, representa lo carnal, lo epicúreo, lo hedonista. ${ }^{4}$ En realidad, es una de las facetas de Nick: la de los impulsos básicos, quizá por eso es representado por un animal, pero es también su guía en el desierto. La unión de ambos (Nick, alto y delgado, representando el idea; Mosh, bajo y gordo, simbolizando el

\footnotetext{
${ }^{1}$ El autor cita como principal influencia a la hora de crear a Nico la vida de San Antonio, sobre todo filtrada por la lectura de La tentación de San Antonio de Flaubert. En http://maxvapor.blogspot.com.es/2012/10/anacoretas.html [Última revisión: septiembre 2013]

2 Todas las citas pertenecen a la edición señalada en la bibliografía de la editorial Edaf, pero hemos pensado que, dada la cantidad de ediciones que existen de este libro, es más útil para el lector citar el número del encabezamiento más que el de la página.

${ }^{3}$ Los datos sobre este personaje son parciales, puesto que sólo aparece en el Evangelio de San Juan. Existe, además, un evangelio apócrifo escrito por la comunidad gnóstica egipcia que lleva su nombre.

${ }^{4}$ El autor dice de él que "es un gato truculento", un liante con mucho desparpajo, un tipo con dobleces que parece que siempre oculta "un as en la manga". En http://maxvapor.blogspot.com.es/2012/10/mosh.html [Última revisión: agosto de 2013]
}

CuCo, Cuadernos de cómic número 1. Septiembre de 2013 
pragmatismo y los apetitos más terrenales) constituye un binomio de personajes de origen literario y cultural ancestral: son una encarnación de Carnal y Cuaresma, don Quijote y Sancho, Ganassa y Bottarga, y un largo etcétera. ${ }^{5}$

El escenario en el que se inicia y en el que transcurre gran parte de la historia es el desierto. Cirlot habla del valor específico del desierto como lugar propicio de la revelación divina: "En cuanto a paisaje en cierto modo negativo, el desierto es el dominio de la abstracción, que se halla fuera del campo vital y existencial, abierto solo a la trascendencia". ${ }^{6}$

Cuando Mosh le pregunta qué está buscando en el desierto, Nick le dice: “iLo absoluto. Lo absoluto y, sin embargo, transparente! Lo que No Pesa pero Cae por su Propio Peso.” (p. 8). ${ }^{7}$ Nick busca la iluminación. Mosh pregunta: “¿Me estás hablando de Dios?", a lo que contesta: "No. Dios es solo una idea contaminada e infecciosa. No persigo ideas, persigo experiencias". Con esta afirmación, Nick resalta que su búsqueda no se circunscribe a un determinado culto, sino que va más allá y busca la experiencia de trascendencia que ofrece cada uno de ellos. En este estadio el conocimiento de lo que busca Nick es puramente intuitivo: se sabe, pero no se conoce; es de alguna forma inefable. De estas experiencias que persigue Nick dice Ram Dass, "percibimos, aunque en general no podamos expresarlo, un significado profundo de nuestra vida. (...) Perdemos nuestro dominio personal, y, no obstante, todo parece armonioso y correcto." 8

Al citar Nick a los padres anacoretas como modelo de lo que quiere hacer, Mosh tacha su discurso de grandilocuente y le recomienda que deje atrás el ego. Mosh encarna el espíritu de la contradicción del ser humano y su baja naturaleza: le recuerda su

${ }^{5}$ Cfr. RILEY, E. C. Introducción al Quijote. Barcelona, Ed. Crítica, 2000, p. 79.

${ }^{6}$ CIRLOT, J. E. Diccionario de símbolos. Madrid, 2006, p. 170.

7 Todas las citas del cómic provienen de MAX. Vapor. Barcelona, La Cúpula, 2012. Para comodidad del lector, en adelante tras cada cita, sólo se señala la página.

${ }^{8}$ Ram Dass en Goleman, D. Los caminos de la meditación. Barcelona, Kairós, 1986, p. 10.

CuCo, Cuadernos de cómic número 1. Septiembre de 2013 
ubicación ("Esto es el desierto, ¿vale? Y aquí todo vale lo mismo. Es la perfecta ho-rizon-ta-li-dad, ¿estamos? ¡Si vas a andar por aquí sintiéndote superior te van a llover hostias por todas partes!", p. 10), pero también le tienta con los placeres terrenales ("Puedo conseguirte lo que desees. Cigarrillos, pastillas, alcohol... ¡chicas!”, p. 11). Como faceta de Nick, Mosh es más de lo que aparenta. Le recuerda a este que está en el desierto: su horizontalidad es simbólica, representa un estado abstracto entre la vida y la muerte, como después veremos. De hecho, cuando ambos se conocen, Nick yace en lo que le parece una sensación de levitación. Algunas viñetas más adelante, Mosh también le indica que deje atrás las mayúsculas para referirse a los grandes conceptos: si quiere avanzar en su propósito tiene que olvidarse de las ideas preconcebidas y acceder a un nuevo nivel de conciencia.

\section{Instintos y apegos}

En este punto, la narración empieza haciendo un cómputo de las semanas que vive Nick en el desierto. Al igual que en la senda sufí, o la ascética, de la iluminación, lo primero que tiene que darse es un aislamiento de los estímulos externos para focalizar la intención. El iniciado debe abandonar la vida mundanal y dedicarse a la búsqueda espiritual. Eso incluye una lucha contra la propia naturaleza, auxiliada por la soledad para poder eliminar los malos hábitos.

En la primera semana, Nick se enfrenta a las pasiones más bajas, como la gula o la lujuria. Siguiendo un estilo iconográfico clásico, ${ }^{9}$ el ave Juanita le trae algo para comer (p. 19), y le conduce al agua, puede saciar su sed y purificarse en ella. Es la primera vez que aparece la metáfora del agua como elemento regenerador y de cambio. Se puede intuir que este uso del agua estará conectado durante toda la obra a la búsqueda de Nick

\footnotetext{
${ }^{9}$ El autor reconoce la deuda del cuadro de Velázquez San Antonio Abad y San Pablo (1635-1638) en la composición de la página 17. En http://maxvapor.blogspot.com.es/2012/10/juanita.html [última consulta: agosto de 2013]
}

CuCo, Cuadernos de cómic número 1. Septiembre de 2013 
desde los inicios de la obra: en el segundo capítulo (p. 15), Nick representa físicamente su búsqueda cuando utiliza el método zahorí de busca de agua para orientarse en el desierto. En esta primera semana, el protagonista se da cuenta de que sus instintos siguen intactos y que la lujuria es aún un apetito a vencer.

En la segunda semana, Nick redobla sus esfuerzos de purificación: "Hago mis ejercicios físicos... mis paseos, mi yoga, mi tai-chi” (p. 26). En el proceso de depuración espiritual, "una vez vacía la mente de todas las distracciones, puede dar comienzo la introversión, la cual concentra la mente en su parte más profunda". ${ }^{10} \mathrm{El}$ siguiente paso es esa introversión, la concentración profunda. Pero Nick aún está lejos de este hito en el camino. En esta segunda semana, el protagonista piensa: "Sin embargo no sé en qué ocupar mis pensamientos. Juanita cubre mis necesidades básicas $(\ldots)^{11}$ Por lo demás, nada sucede. (...) Intento meditar, pero me pierdo en divagaciones sin sentido... que terminan invariablemente en salvajes fantasías sexuales" (p. 26-27). ${ }^{12}$

Ese embrollo en la cabeza de Nick se hace real, por así decirlo, en un espesísimo bosque-zarzal que allí aparece. En este momento el conflicto interior se hace exterior, la metáfora toma cuerpo. ${ }^{13}$ La ayuda de un enano llamado Hércules se convertirá en fundamental: montado en un cerdo, se encargará de limpiar (¿una alusión a los titánicos trabajos de Hércules?) todo ese matorral de pensamientos en inquietudes (FIG. 1), pues

\footnotetext{
${ }^{10}$ Goleman, D. Op. cit. p. 102.

11 Entre las orientaciones a los hesicastas cristianos, se recomienda el retiro en una celda silenciosa, comer solo lo que uno necesite para mantener la vida, y la contemplación, entre otras cosas.

${ }^{12}$ El abad Geroncio de Petra escribe a este respecto: "Muchos de los que son tentados de deleites corporales, aunque no pequen corporalmente, pecan de pensamiento. Y aunque conserven la virginidad corporal, fornican en su alma. Por eso, carísimos, bueno es hacer lo que está escrito: 'Por encima de todo cuidado, guarda tu corazón."”

${ }^{13}$ O al revés: el autor ha comentado que en la p.29, "había que plantear una transición desde el mundo exterior - el desierto - al mundo interior — la mente de Nick — que solo se podía resolver con audacia puramente visual", en referencia a la escena de Hércules, que para el protagonista es puramente imaginaria. En http://maxvapor.blogspot.com.es/2012/11/tercer-capitulo.html [Última consulta:
[Ü septiembre de 2013]
}

CuCo, Cuadernos de cómic número 1. Septiembre de 2013 
como dice Nick: "No se puede abandonar la civilización cargando con los trastos viejos" (p. 29). Hércules es también una emanación de Nick (despejar el bosque se convierte en purgar la mente de Nick de todos los apegos): su trabajo no se completará hasta la página 64, cuando el protagonista ya ha alcanzado un nuevo nivel de progreso.

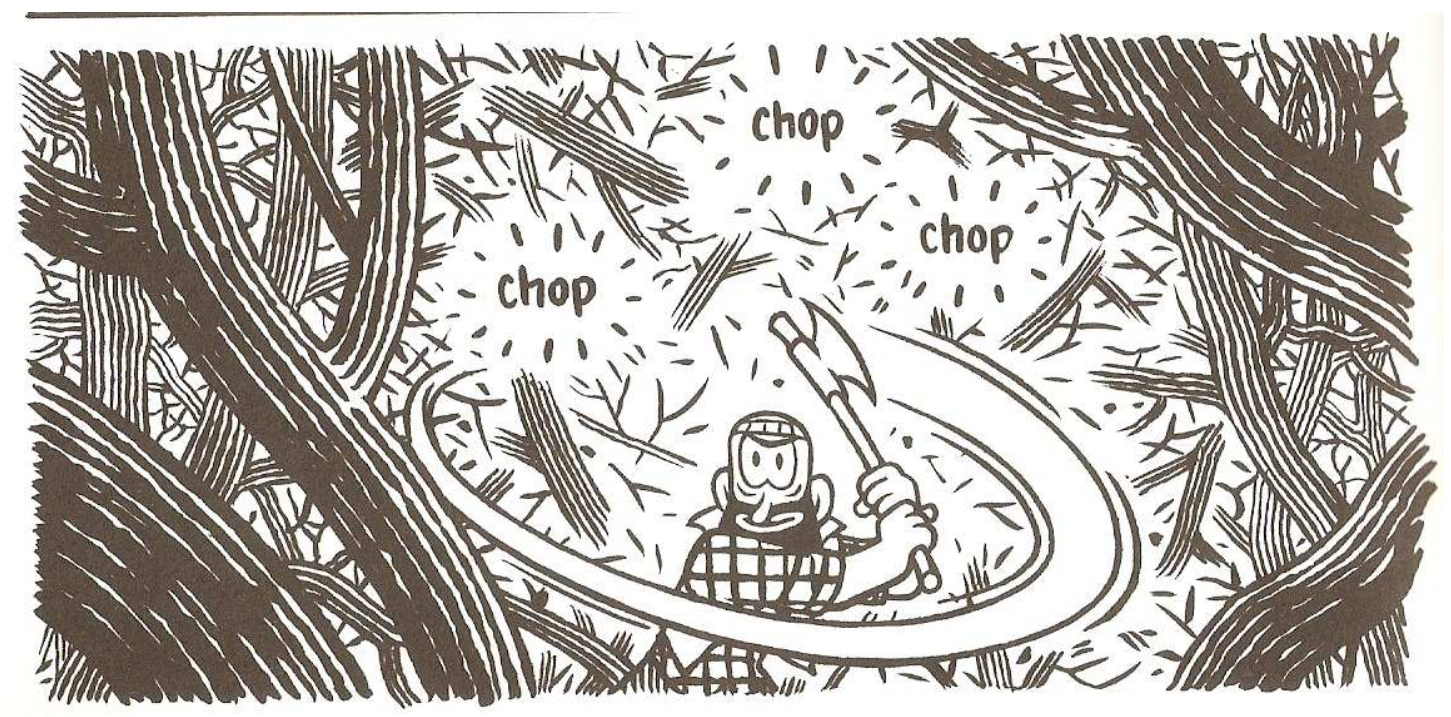

FIG. 1. Hércules desbrozando el desierto.

En la conversación que sigue con Mosh, Nick le pone en aprietos inquiriéndole sobre la naturaleza de sus tentaciones, y se constata que estas son de origen interior: “¡Venga, hombre, solo te estaba poniendo a prueba! Quería saber qué clase de tipo eres" (p. 34). Es aquí donde por primera vez se menciona a Vapor, a través de Mosh. Este le indica que es "como Dios, o algo así (...) Tiene siglos, solo las piedras son más viejas que él.” (p. 35), y, en una anticipación del relato, nos dice que ya lo entenderá cuando lo vea. Si Mosh, como veremos, representa el inconsciente, la primera certeza que se tiene de Vapor llega desde la intuición, desde un atisbo casi sugerido de la conciencia.

CuCo, Cuadernos de cómic número 1. Septiembre de 2013 


\section{La unidad sobre la dualidad}

Cada vez que sus cavilaciones se alejan de su ascenso y vuelven a lo trivial, Nick recibe una pedrada en la cabeza. Es el toque de atención del meditador, que requiere que la mente vuelva a concentrarse. En la tercera y cuarta semana de estancia en el desierto tenemos una escena clave: el diálogo con la sombra de Nick, que también intenta hacerle desistir de su propósito, consciente de que ello supone su disolución. La sombra se anuncia como la parte oscura de Nick: "¿Quién crees que carga con tus malos rollos, con tus deseos sucios e inconfesables, con tus vicios más sórdidos?” (p. 44). Nick se enfrenta a ella desde la posición del loto, de forma calmada y meditativa, al contrario que la sombra, que va haciéndose cada vez más larga, angulosa y agresiva. En este punto Max utiliza un recurso gráfico genial para representar la desesperación cada vez más exagerada de la sombra: esta se va a haciendo más y más larga, de forma que termina convirtiéndose en la separación de viñetas de la página. Así como la discusión va avanzando, la sombra se ensancha, hasta que, vencida por la persistencia de Nick, pierde consistencia y finalmente se marcha, dejando a nuestro protagonista sin su oscuro reflejo.

Podríamos establecer una correlación entre los términos freudianos de consciente, subconsciente e inconsciente, y los personajes de Nick, la sombra y Mosh, respectivamente. Aunque sean categorías que la psicología ya ha abandonado, nos sirven para entender un poco más esa lucha interior que sostiene el protagonista. Nick sería el consciente, la afirmación de la voluntad, mientras que su sombra actuaría como el subconsciente o preconsciente, es decir, la barrera entre lo consciente (Nick) y el inconsciente (Mosh). En términos más modernos, hablaríamos del Ello (que representa los impulsos y deseos más elementales), que sería el gato Mosh; el Superego (que representa los pensamientos morales y éticos recibidos culturalmente), que sería la 
sombra, y el Ego (la entidad que funciona como mediadora entre las demandas del Ello y del Superego), que estaría representado por Nick. ${ }^{14}$

Así, durante la cuarta semana en el desierto, Nick se duele de la falta de sombra. Con su eliminación, se siente vacío, incompleto, "como un fantasma, como un espectro" (p. 50). Ha perdido parte de su humanidad. "Soy solo la idea de Nicodemo... el dibujo de Nick" (p. 51). Y a continuación: "Y ahora ya solo me queda un doble en el mundo" (p. 51), ¿se refiere a Mosh, el único avatar que queda diferenciado de su ser? Efectivamente, la pérdida de la sombra es un paso más hacia un nuevo estado, que Max refleja de forma genial dibujando al Nick con cada vez menos trazos, hasta casi la inconsistencia. Se trata de una anticipación del final: en esta ocasión, Nicodemo ha estado cerca de la disolución final del yo. Pero aún quedan cosas por asimilar en su búsqueda.

A continuación, Nick tiene un sueño sobre un gigante de hielo y otro de carbón que se autodestruyen en una lucha. En la obra de Max, el uso de los sueños es muy habitual. Este recurso aparece asiduamente en obras como El prolongado sueño del sr. T. (1998), Bardín el superrealista (2006), o la reciente Paseo astral (2013), siempre como una forma de autoconocimiento, de mensaje que el subconsciente envía al consciente. ${ }^{15}$ En esta ocasión, el sentido del sueño es explicado de inmediato: como le dice el personaje del tonel, ambos son representaciones de sí mismo y su enfrentamiento interior no tiene sentido: "el combate es inevitable, pero también inútil" (p. 59). Este personaje le indica que repare atención en el final del sueño, donde los gigantes muertos son sepultados por la nieve: “tú eres también la nieve, ligera y leve. Déjate fundir, déjate

\footnotetext{
${ }^{14}$ FreUd, S. Obras completas de Sigmund Freud. Volumen XIX. El yo y el ello, y otras obras (1923-1925). 1. El yo y el ello (1923). Traducción José Luis Etcheverry. Buenos Aires \& Madrid: Amorrortu editores.

${ }^{15}$ El autor dice a propósito de esta secuencia: “¿Cómo era posible que no hubiera previsto en el guión ni un solo sueño para Nick? Y de pronto me pareció muy lógico que alguien que está en un desierto sueñe con montañas nevadas. $\mathrm{Y}$ la nieve me llevó al agua, y el agua al vapor..." En http://maxvapor.blogspot.com.es/2012/11/el-azar-benevolente.html [Última consulta: septiembre de 2013]
} 
fluir, déjate evaporar" (p. 59). Nos encontramos ante una nueva anticipación del relato que señala el carácter taoísta de esta historia: se nos indica que no se trata de una dualidad alma-cuerpo, de una lucha porque un elemento se imponga al otro, sino de una unidad superior que abarca ambas realidades. El Tao dice: "Cuando todo el mundo reconoce lo bueno como bueno, esto en sí mismo es malo. (...) lo oculto y lo manifiesto se generan el uno al otro. Dificultad y facilidad se complementan entre sí." (Tao, II). Según el Génesis, el inicio de la distinción entre el bien y el mal, lo bello y lo feo, marca el inicio del pecado original, esto es, la separación y el comienzo de la dualidad. El Tao, en cambio, habla de una dualidad superada y abarcada de nuevo en la unidad: "El cielo alcanzó la Unidad y se hizo diáfano; la tierra alcanzó la Unidad y se volvió tranquila (....). Todos ellos son lo que son en virtud de la Unidad.” (Tao, XXXIX). No es extraño, pues, que el personaje del tonel elija la metáfora del agua para explicar este proceso. Esta metáfora ha evolucionado desde la consistencia de la nieve, que como sólido es su representación física, hasta la inaprensividad del vapor, símbolo de lo incorpóreo, de lo intangible y por tanto de lo trascendente. Pero Nick aún no está preparado para esta revelación. Tiene que llegar más allá, hasta un punto en que la conciencia, hasta ahora concentrada en un solo punto, desaparezca también.

\section{4. Última tentación e iluminación}

Durante la quinta semana en el desierto que sigue a su sueño, Nick se lamenta de lo que ha dejado atrás: el placer de los sentidos y de la carne, cosa que un nuevo ladrillo se encarga de cortar. Pero es ya la última vez: está ya en el camino de la iluminación. Una pequeña viñeta única en una página en blanco nos devuelve a Hércules, que señala que ha terminado con la poda que llevaba a cabo. Nico ha accedido a un nuevo nivel. Despertando de un sueño (recordemos: entre el sueño y la muerte), ${ }^{16}$ y siguiendo la

16 "Cuando la atención de la mente está por completo desviada y retirada de los sentidos corporales, recibe el nombre de éxtasis. Entonces, los cuerpos que puedan estar presentes no se ven con los ojos

CuCo, Cuadernos de cómic número 1. Septiembre de 2013 
metáfora que se desarrolla en torno al agua, un potente aguacero (p. 67) le lleva a vislumbrar la felicidad del instante (el verdadero significado del clásico carpe diem), un breve momento de gozo que conecta con sus recuerdos de infancia, en el que Nico se funde con el agua para, de una forma superficial, intuir lo que hay más allá ("Entonces... ¡La felicidad es esto! Chapotear en el instante fugaz, luminoso e inasible..", p. 68).

No obstante, al terminar el chaparrón, le hace caer en un enorme enfado, la última de sus recaídas espirituales. Esta experiencia cercana al nirvana le afecta de dos formas diferentes: en la primera, deja sentir su frustración por lo infructuoso de su empeño (pp. 69-71); por otro, puede entender lo que ha ocurrido desde la contemplación (pp. 72-74). Esta última escena es diseñada por el autor sin solución de continuidad desde la anterior y con una conceptualización mucho más fuerte. Max lo remarca gráficamente al convertir a Nico en un corazón, y estilizándolo hasta el vacío de la abstracción.

¿Por qué esta doble respuesta a un mismo fenómeno? Quizá porque por su naturaleza y novedad, es difícilmente explicable o racionalizable. En este tipo de experiencia, que como indica Ram Dass, puede producirse tras leer un libro, admirar una obra de arte, en el contexto de un paraje natural idílico o tras un acontecimiento traumático, "perdemos nuestro dominio personal y, no obstante, todo parece armonioso y correcto". ${ }^{17}$ Cuando esto ocurre, nuestra mente analítica pugna por etiquetar la experiencia de algún modo, sea desde el punto de vista científico o espiritual, que permita categorizarla en nuestros esquemas de pensamiento.

A continuación Nico llega a la montaña. Nótese el hecho que después de esta breve iluminación, el tiempo deja de tener sentido, por lo que no hay más referencias a

abiertos, ni se oye voz alguna. Es un estado a medio camino entre el sueño y la muerte". ButLER. Western Mysticism. Harper, 1996, p. 50.

${ }^{17}$ Ram Dass, en Goleman, D. Op. cit., p. 10.

CuCo, Cuadernos de cómic número 1. Septiembre de 2013

CuCoEnsayo 
las semanas que Nick está en el desierto, y lo que se ha distribuido anteriormente en capítulo de 8-12 páginas, ahora ya será un continuo que fluye hasta el final de la obra.

La montaña en la que Nico pasa la última estancia de su periplo desierto ejerce un violento contraste con la planicie del desierto. Su altura simboliza el ascenso del intelecto, la fuerza, la estabilidad, la inmutabilidad. Con la llegada a este nuevo escenario, se ha operado un cambio en Nick, que parece más sosegado, tranquilo y meditativo. En conceptos de la meditación trascendental, diríamos que ha entrado dentro del nivel de la conciencia cósmica. Una vez en este estado,

la conciencia trascendental (...) persiste en otros estados. [El meditador] observa que en comparación los placeres sensuales no son tan encantadores como antes. (...) Su estado es de ecuanimidad: la turbulencia y excitación de las emociones intensas — temor, pesar, enojo, depresión y anhelo- están suavizadas por un estado permanente de 'alerta reposada'. ${ }^{18}$

Nick es ahora capaz de hablar con Mosh de forma distendida y de por fin hallar paz en su reclusión: ya no discute con él, sino que mantiene una conversación, a la vez intrascendente y zen, sobre las formas de las nubes. (p. 78). En palabras del Tao: "El Sabio solo sonríe como un niño divertido" (Tao, XLIX). En la cima de la montaña, el ave Juanita acude a verlo, pero no le trae sustento; solo hablan del tiempo: otra indicación de que, por fin, nuestro protagonista ha dejado atrás sus necesidades más mundanas.

${ }^{18}$ Goleman, D. Op. cit, p. 119.

CuCo, Cuadernos de cómic número 1. Septiembre de 2013 


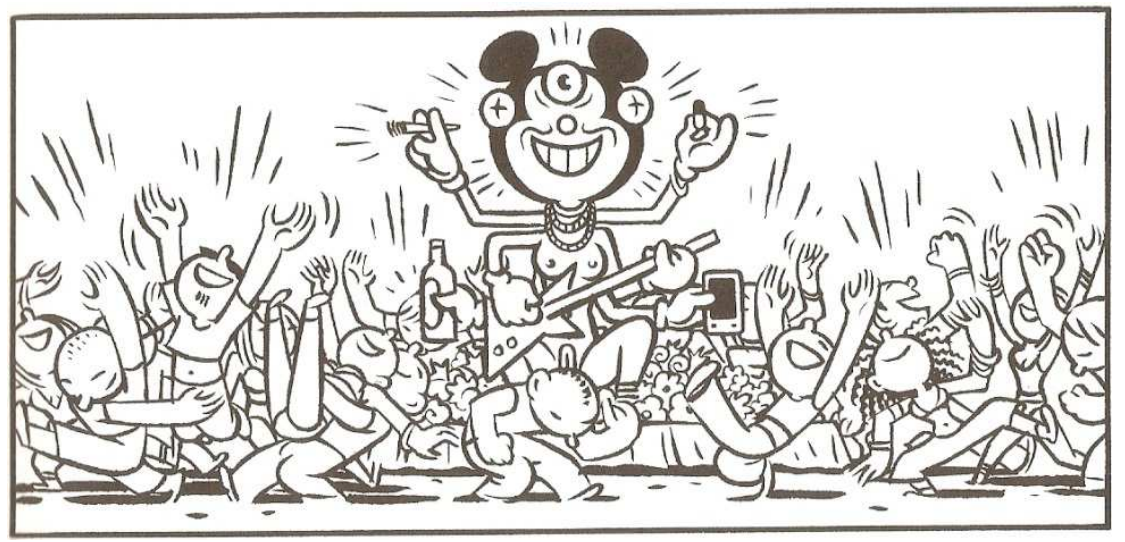

FIG. 2. El cortejo de la Reina de Saba.

Finalmente, la última prueba en el camino de Nick viene de la mano del cortejo de la Reina de Saba, que con su desfile (FIG. 2) representa todas las pasiones del plano físico (Mosh le ofrece unas gafas de "realidad" para ver el pasacalles): la pompa y el oropel, la violencia y la guerra, la lujuria y la fama, la gula y el poder, el éxtasis y la evasión de la realidad. ${ }^{19}$ La Reina intenta seducir a Nick de forma sibilina, apelando tanto a valores racionales como emotivos, pero este está por encima de sus tentaciones. Nick ataja la conversación citando una letra del grupo Dinosaur Jr. (que el autor utiliza como cita inicial en la obra): "Yo también a veces siento el dolor de todos, y después... después no siento nada”. El Tao diría: "Quien observa el Tao no desea estar lleno" (Tao, XV). Nick ha superado la última prueba que le ata a los placeres mundanos. Como lo expresa de nuevo el Tao: "Cuando se gobierna el mundo conforme al Tao, los demonios carecen de poderes espirituales" (Tao, LX). Ha llegado la hora de conocer a Vapor.

En una escena semejante a la secuencia de la aparición de la sombra y del aguacero, señalando el continuo, de la evolución de Nick, aparece la silueta de Vapor. El Tao diría: "¡Míralo, pero no puedes verlo! Su nombre es Sin-Forma” (Tao, XIV).

\footnotetext{
${ }^{19} \mathrm{El}$ autor comenta a propósito: «pretendía reflejar todo lo "tóxico" de la actualidad, lo peor de nuestro mundo convertido en show para las masas». En http://maxvapor.blogspot.com.es/2013/02/el-desfile-yii.html [Última consulta: septiembre 2013]
}

CuCo, Cuadernos de cómic número 1. Septiembre de 2013 
Vapor anuncia el fin de su preparación ("Has visto lo que había que ver y has hecho lo que había que hacer", p. 102) y le insta a unirse a él. "Vapor se disgrega, Vapor se condensa. Ninguna forma lo limita, nada lo desgasta. Vapor no tiene contingencias, no tiene ideas ni emociones, no siente miedo, dolor ni hambre." (p. 104). De la misma forma, el Tao dice: "El Tao es como una taza vacía que, al usarse, nunca se puede llenar. Insondable, parece ser el origen de todas las cosas. Embota las aristas afiladas, deshace los enredos, armoniza todas las luces, une al mundo en un todo. Oculto en las profundidades, parece existir eternamente". (Tao, IV) Aunque Nick se muestra escéptico tras lo que ha visto en el desierto, sobre todo de la experiencia con la Reina de Saba, y también duda de esta última revelación. Es el último peldaño antes del final, en el que se duda de todo lo conseguido hasta el momento. En el diálogo entre Vapor y Nick se dice:

Vapor: Una vez, hace mucho, Vapor fue como tú, como Antonio, Pablo, Simón...

Nick: Los santos anacoretas, los padres del Desierto.

Vapor: Ellos alcanzaron la santidad, Vapor fue un poco más allá... Ellos eligieron la rigidez. Vapor supo ser flexible (p. 103).

Vapor está por encima de las ideologías y las creencias, remite al fenómeno de la iluminación en sí mismo. El Tao menciona: "Lo duro y lo rígido son compañeros de lo muerto: lo blando y lo flexible son compañeros de lo vivo." (Tao, LXXVI). Vapor puede indicar aquí que su meta, su transustanciación, aunque parecidas en su proceder a otras vías (la de los anacoretas), no buscaba a un Ser ajeno a él, sino su propia conversión en el fenómeno.

Ante las últimas dudas escépticas de Nick, que piensa que Vapor pueda ser otra trampa del ego, que intenta prevalecer, Vapor dice “¿Acaso has renunciado a todo para ir en pos de nada? En el punto en el que estás solo te quedan dos opciones, Nick: fundirte con Vapor para la eternidad o pudrirte en este desierto. Tú eliges, Nick...” (p. 106) (FIG. 3). El Filocalia de los hesicastas cristianos define muy bien esta experiencia 
de abrazo y fusión del alma con lo intangible: "Entonces, abandonando lo numeroso y lo variado, nos fundiremos con el Uno, el Único y el Unificador, directamente en una unión que trasciende la razón". ${ }^{20}$

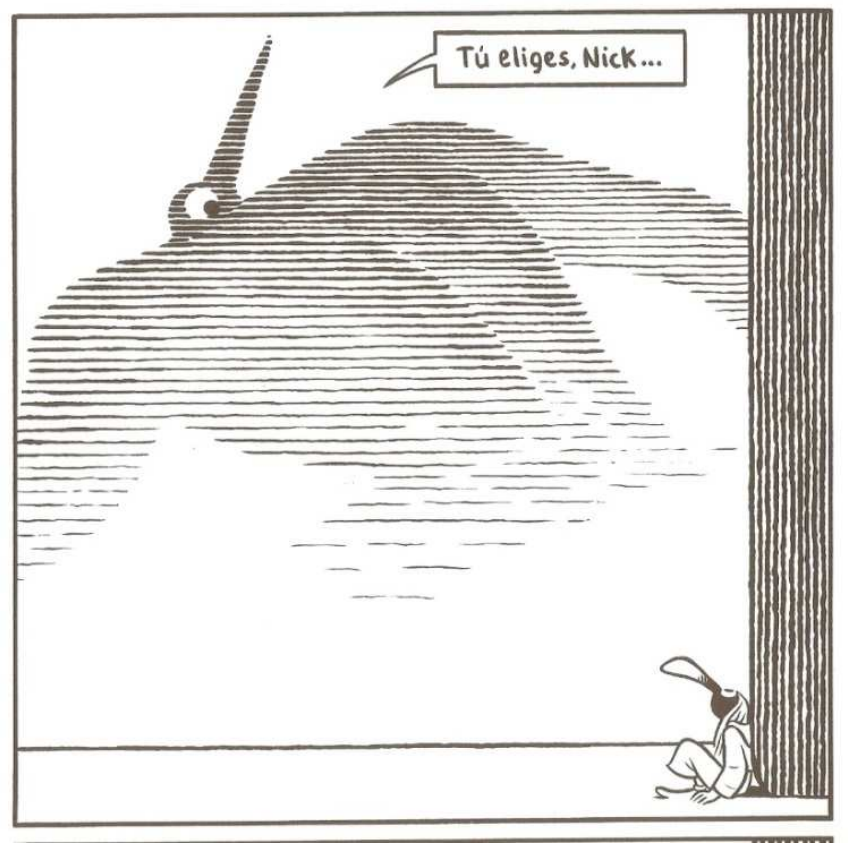

FIG. 3. Nick y Vapor.

El final, como dice Vapor, está en las manos del protagonista, y con la página en blanco (p. 111) que despide este encuentro, Max deja al arbitrio del lector decidir lo que acontece finalmente. Con todo, parece obvio, o esta es al menos nuestra interpretación, que Nick ha encontrado por fin lo que anhelaba al principio de la obra: Lo absoluto y, sin embargo, transparente. Lo que No Pesa pero Cae por su Propio Peso. Se ha producido la última transformación en la conciencia de Nick. Este proceso extingue su yo pasado (de ahí su desaparición) y lo hace renacer en un nuevo nivel de experiencia. Llegados a este punto, el Tao resume perfectamente lo acontecido con estas palabras (las cursivas son nuestras):

${ }^{20}$ Citado por Goleman D. Op. cit., p. 100.

CuCo, Cuadernos de cómic número 1. Septiembre de 2013 
Alcanza el supremo Vacío. Abraza la paz interior con corazón decidido. (...) Encontrar paz es realizar el propio destino. Realizar el propio destino es ser eterno. A conocer lo Eterno se le llama Visión. (...) Si se conoce lo Eterno, todo se puede comprender y abarcar. Si se puede comprender y abarcar todo, se es capaz de ser justo. Ser justo es ser como un rey; ser como un rey es ser como el cielo. Ser como el cielo es ser uno con el Tao; ser uno con el Tao es permanecer para siempre. Alguien así estará a salvo y entero, incluso tras la desintegración de su cuerpo.

La historia de Nick acaba aquí, pero no la obra. La suya ha sido una búsqueda y una salvación individual, como lo son todas. El mismo autor comenta:

\begin{abstract}
"Vapor" podría haber terminado tranquilamente con la última viñeta del capítulo anterior, con Nick perplejo ante la propuesta de Vapor. Pero desde el principio tuve claro que había que volver con los habitantes del desierto para cerrar la historia. (...) La vida sigue en el desierto, igual que siglos antes, igual que siglos después. Nicodemo ha sido una estrella fugaz que ha brillado apenas unos segundos en la eternidad desértica. ${ }^{21}$
\end{abstract}

En el desierto, pues, un escenario infinito y atemporal, quedan esas necesidades vitales (Juanita) y apetencias (Mosh) que se dejan atrás en este proceso de ascenso de la conciencia.

\begin{tabular}{|c|c|c|}
\hline \multirow{9}{*}{ 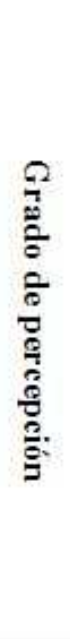 } & $\begin{array}{l}\text { Hitos en la senda de la percepción } \\
\text { (Goleman) }\end{array}$ & Aplicación en Vapor \\
\hline & Cese total de la conciencia. & Disolución en Vapor. \\
\hline & $\begin{array}{l}\text { Nirvana: la conciencia deja de tener } \\
\text { un objeto. }\end{array}$ & Encuentro con Vapor. \\
\hline & Percepción sin esfuerzo. & Nick en la montaña. Cortejo de la Reina de Saba. \\
\hline & Comprensión. & Éxtasis del corazón. \\
\hline & Pseudonirvana. & Secuencia del aguacero. \\
\hline & Etapa de reflexiones. & Nick y la sombra. Sueño de los gigantes. \\
\hline & $\begin{array}{l}\text { Atención a las funciones corporales y } \\
\text { objetos de la mente. }\end{array}$ & Primeras semanas en el desierto. Hércules. \\
\hline & Concentración de acceso. & Inicio, primera conversación con Mosh. \\
\hline
\end{tabular}

FIG. 4. De abajo a arriba, hitos en la senda de la percepción aplicados a Vapor (elaboración propia).

\footnotetext{
${ }^{21}$ En http://maxvapor.blogspot.com.es/2013/03/el-epilogo.html [Última revisión: agosto 2013]
} 
Como explica Goleman, la experiencia de la felicidad sublime parte de un adiestramiento completo que permite al meditador hacer su mente manejable y flexible. El quid de este adiestramiento comienza con la atención, continúa a través de la percepción hasta llegar al nirvana y más allá, cuando cesa todo pensamiento y el espíritu finalmente es libre. ${ }^{22}$ Como complemento final de nuestro trabajo, en la tabla de la FIG. $\underline{4}$, hemos querido realizar una correspondencia con esos estados de la percepción que llevan a la liberación y su reflejo en Vapor.

La práctica de la percepción empieza en el punto en el que la atención prosigue sin intervalos, y abarcaría los dos primeros estados de esta senda. El meditador logra la capacidad de percibir los pensamientos que interfieren en su práctica. Se trata de una concentración de acceso, todavía precaria, que da paso a la atención a la función corporal, las sensaciones físicas, los estados mentales y los objetos de la mente. Estos estados se corresponden en Vapor con el inicio de la estancia en el desierto de Nick y la interferencia de sus necesidades físicas (agua) y de sus apetitos (comida y sexo).

En la etapa de reflexiones, la conciencia y sus objetos se perciben en cada momento como procesos distintos y separados: esto explicaría las emanaciones de la conciencia de Nick, que se desdobla, o más bien se proyecta, como hemos visto en Hércules, y en la sombra. En esta etapa, el meditador observa que su mente contempladora y los objetos de esta vienen y van, y se da cuenta de la impermanencia del ser. Cuando Nick deja atrás este estado llega al pseudonirvana, una claridad de percepción que provoca "una felicidad sublime que cubre el cuerpo del meditador, una dicha sin precedentes que parece no tener fin" y "una percepción rápida y clara de cada momento de conciencia: la observación es aguda, fuerte y lúcida". ${ }^{23}$ Pero es esta una etapa más en el camino y no su consecución. El meditador ha de cuidarse de no ser engañado confundiendo lo que no es la senda con la senda. Se trata de la comprensión:

\footnotetext{
${ }^{22}$ Goleman, D. Op. cit., p. 52 y ss.

${ }^{23}$ Ibíd., p. 60.
} 
en Vapor lo veríamos cuando Nick reacciona de forma dual a la revelación del aguacero, como hemos explicado anteriormente. En ese momento, tras la lucha por no fracasar en la prosecución de la percepción debido al apego a esos fenómenos, el meditador se da cuenta de que esas experiencias son un hito hacia su destino final. En dicho punto, la percepción de cada momento de conciencia resulta más clara: se ha llegado a la percepción sin esfuerzo. Cesan las sensaciones de temor, desesperación y angustia. El meditador ve todos los fenómenos mentales como limitados, carentes de deseabilidad, ajenos. Es el estadio al que ha llegado Nick tras su crisis, cuando por fin está en paz consigo mismo en la montaña (nótese cómo explica a su manera esa inmanencia e imperturbabilidad de los sentidos comparándose con su entorno: "Estas rocas y este cielo son ahora mi piel. Su respiración es la mía. No necesito más.”, p. 77), y cuando desciende para ver el cortejo de la Reina de Saba, cuyas tentaciones rechaza de forma natural. En este estado, previo al nirvana, "emergen una claridad mental sublime y una ecuanimidad omnipresente". ${ }^{24}$ Nick le dice a la Reina de Saba: "Sabes ser persuasiva y tu voz es terriblemente seductora... pero aunque estés ahí en la oscuridad, veo a través de ti (...). Eres falsa y embustera, y tu negrura es más negra que la misma oscuridad" (p. 99). Una vez superado este estado, se llega al nirvana, con la extinción absoluta de todo deseo y tentación, la carencia de egoísmo y una percepción en la que se sabe "cómo es todo realmente y cómo aparece". ${ }^{25}$ Nick ha "despertado" al estado Vapor, a un nuevo nivel de conciencia cósmica en la que el yo se disuelve (Vapor habla en tercera persona: "Vapor solo baila una danza sin fin en la pureza de lo infinito.", p. 105). Precisamente, el meditador que llega al nirvana es un arahant, "el que ha despertado, el que es digno de veneración". No se trata de una iluminación pasajera venida de una conciencia externa ("Ellos alcanzaron la santidad, Vapor fue un poco más allá... Ellos eligieron la rigidez. Vapor supo ser flexible”, p. 103), sino un cambio permanente en el ser. A la proposición de Vapor de fundirse con él, Max deja la

\footnotetext{
${ }^{24}$ Ibid., p. 64.

${ }^{25}$ Ibíd., p. 71.
}

CuCo, Cuadernos de cómic número 1. Septiembre de 2013 
incógnita al lector con el fundido en blanco que antes hemos mencionado, pero este recurso nos viene muy bien para llegar al último peldaño de esta senda de la percepción. En el último estado, más allá del nirvana, es el llamado nirodh ("cese"). En el nirvana, el objeto de la conciencia desaparece, pero en nirodh es la conciencia la que cesa por completo. En el plano físico real, este estado corresponde con aquellos meditadores cuyo latido cardíaco y metabolismo cesan junto a la conciencia, o más bien, continúan bajo el umbral de la percepción: "los procesos metabólicos prosiguen a un nivel residual, y el cuerpo del meditador no se pudre como el de un cadáver". ${ }^{26}$ Es el caso de algunos yoguis hindúes o monjes tibetanos, que pueden estar largas temporadas sin consumir alimentos, o el conocido y ya citado aquí San Simón el Estilita, del que se dice que pasó 37 años en una pequeña plataforma sobre una columna.

Con todo, este último estadio de nirodh no es la meta final en muchas de las tradiciones meditativas. En el budismo, por ejemplo, el iluminado puede renunciar al nirodh para poder enseñar el camino de la iluminación a sus congéneres. Por eso es interesante señalar a Wilber, que dice que "en las tradiciones no duales te comprometes, mediante un voto muy sagrado (un voto que es, al mismo tiempo, el fundamento de toda tu práctica) a no desvanecerte en la cesación, a no ocultarte en el nirvana, a no evaporarte en nirodh". ${ }^{27}$ Creemos que el uso de la metáfora del vapor que también elige Wilber para describir este último estado de disolución no es casual. La cita sigue:

Con este voto, te comprometes a cabalgar la ola del samsara hasta que todos los seres atrapados en ella puedan reconocerla como una manifestación de la Vacuidad; te comprometes asimismo a atravesar la cesación y la no dualidad tan rápidamente como te sea posible, para poder ayudar a todos los seres a reconocer lo No Nacido en medio de la misma existencia.

\footnotetext{
${ }^{26}$ Ibíd., p. 74.

${ }^{27}$ WILBER, K. La plena conciencia de ser. Barcelona, Editorial Kaidós, 2006, p. 302. Las cursivas son nuestras.
}

CuCo, Cuadernos de cómic número 1. Septiembre de 2013 
No deja de ser interesante el hecho de que esta senda de la percepción, que Goleman reelabora a partir de las enseñanzas del Visuddhimagga, un texto budista del s. v, pueda aplicarse con tanta naturalidad al devenir de la trama de Vapor.

\section{Conclusión}

Una de las definiciones que se han dado del Tao es "El Tao es la Totalidad Creadora manifestada en la Unidad que se oculta en la diversidad". Creemos que esta sentencia puede resumir tanto el sentido de la búsqueda de Nick en Vapor como definir al propio personaje de Vapor que, como ente, representa un estado superior de la conciencia al que se accede solo a través del abandono previo de los lazos mundanales. De esta forma, la obra conecta con las diferentes tradiciones meditativas, que, así señaladas, se revelan como variaciones de un proceso único para la transformación de la conciencia, objetivo último que todas persiguen con diferentes nombres: samadhi, zazen, iluminación, unión con Dios... o, en nuestro caso, Vapor.

En su blog, Max plantea la génesis de su obra en estos términos: “Cómo sería un anacoreta en el mundo de hoy, en el que ya nadie cree ni en dios ni en el diablo? ¿Qué podía llevarle a retirarse voluntariamente a la soledad del desierto?". ${ }^{28} \mathrm{Al}$ comentar la tesis detrás de Vapor, el autor afirma que "decidí partir de una premisa argumental, la de que ni lo místico ni lo sobrenatural iban a tener un papel en la historia, simplemente porque no lo tienen en nuestra sociedad occidental". ${ }^{29} \mathrm{Y}$, sin embargo, creemos que, en la obra, la mística y Dios sí tienen un papel importante, quizá no desde una perspectiva de la cultura judeocristiana occidental, sino más bien desde una aproximación a la idea de Dios como la aspiración del hombre a lo inmanente, lo inefable y lo trascendente. La historia de Max es moderna, sí, pero también atemporal, y la riqueza y variedad de los

\footnotetext{
${ }^{28}$ En http://maxvapor.blogspot.com.es/2012/10/anacoretas.html [Última revisión: septiembre de 2013]

${ }^{29}$ En http://maxvapor.blogspot.com.es/2012/10/tesis-que-tesis.html [Última revisión: septiembre de 2013]
}

CuCo, Cuadernos de cómic número 1. Septiembre de 2013 
elementos que el autor toma para configurar Vapor la convierte así en una obra sincrética y ecléctica que logra unir todas esas tradiciones en una única historia.

\section{Bibliografía}

Goleman, D. Los caminos de la meditación. Barcelona, Editorial Kairós, 1986.

MAX (CAPdEVILA, F.). Vapor. Barcelona, La Cúpula, 2012.

Merton, T. La sabiduría del desierto. Madrid, Biblioteca de autores cristianos, 1997.

TsE, L. Tao Te King. Madrid, Edaf, 2003.

VVAA: Los dichos de los Padres del desierto. Buenos Aires, Ediciones Paulinas, 1986.

WILBER, K. La plena conciencia de ser. Barcelona, Editorial Kaidós, 2006. 